\title{
Atendimento Educacional Especializado nos Institutos Federais: Reflexótes sobre a Atuaçáo do Professor de EducaÇão Especial ${ }^{1}$ SPECIALIZED EDUCATIONAL SERVICE at the FEDERAL INSTITUTES: ReFLECTIONS on the Performance of the SPECIAL EDUCATION TEACHER
}

\author{
Ana Paula ZERBATO2 \\ Carla Ariela Rios VILARONGA ${ }^{3}$ \\ Jéssica Rodrigues SANTOS ${ }^{4}$
}

\begin{abstract}
RESUMO: Os Institutos Federais de Educação têm como objetivo promover o desenvolvimento de ações que garantam a inclusão social das pessoas com deficiência e em vulnerabilidade social. Assim sendo, as matrículas de estudantes Público-Alvo da Educação Especial (PAEE) propuseram novos desafios, tanto na Educação Básica de nível médio quanto no ensino técnico e tecnológico. Dessa forma, este artigo teve como objetivo geral discutir a atuação do professor de Educação Especial no contexto educacional dos Institutos Federais. Como objetivos específicos, pontuou-se: analisar documentos normativos que tratavam da atuação desse professor na Educação Básica de nível médio técnico e tecnológico e refletir sobre a atuação do professor de Educação Especial, de modo a traçar um paralelo entre um estudo de caso e os documentos normativos existentes. Trata-se de uma pesquisa documental, de abordagem qualitativa. Foram levantados os documentos normativos que se referiam ao papel da Educação Especial e analisados relatórios que retratavam da atuação de uma professora de Educação Especial em um dos campi do Instituto Federal Baiano. Os resultados apontaram que o Atendimento Educacional Especializado e a garantia do Educador Especial é prevista para a Educaçâo Básica, porém essa é a realidade de um número pequeno de Institutos Federais. Destacou-se a relevância do trabalho especializado para escolarização dos estudantes PAEE e a parceria com outros profissionais no apoio dos estudantes com necessidades específicas. Concluiu-se que a presença do profissional de Educação Especial é indispensável na construçáo de ações em conjunto de curto, médio e longo prazo que possibilitem participação e aprendizagem dos estudantes PAEE.
\end{abstract}

PALAVRAS-CHAVE: Educação Especial. Inclusão escolar. Ensino Médio. Ensino técnico. Educação profissional.

\begin{abstract}
The Federal Institutes of Education aim to promote the development of actions that guarantee the social inclusion of people with disabilities and in social vulnerability. Hence, the enrollment of the Target Students of Special Education proposed new challenges, both in High School Education and in technical and technological education. Thus, this paper aimed to discuss the performance of the Special Education teacher in the educational context of the Federal Institutes. As specific objectives, it was pointed out: to analyze normative documents that dealt with the performance of this teacher in Technical and Technology-focused High School and reflect on the performance of the Special Education teacher, in order to draw a parallel between a case study and the existing normative documents. It is a documentary research, with a qualitative approach. The normative documents referring to the role of Special Education were raised and reports were analyzed that portrayed the performance of a Special Education teacher on one of the campuses of the Federal Institute of Bahia, Brazil. The results showed that the Specialized Educational Service and the Special Educator guarantee is provided for Basic Education, however this is the reality of a small number of Federal Institutes. The relevance of specialized work for the schooling of the Target Students of Special Education and the partnership with other professionals in supporting students with specific needs was highlighted. It was concluded that the presence of the Special Education professional is indispensable in the construction of joint actions in the short, medium and long term that enable participation and learning by the Target Students of Special Education.
\end{abstract}

KEYWORDS: Special Education. School inclusion. High School. Technical education. Professional education.

\footnotetext{
${ }^{1}$ https://doi.org/10.1590/1980-54702021v27e0196

${ }^{2}$ Doutora em Educação Especial pela Universidade Federal de São Carlos (UFSCar). Docente da Faculdade de Educação da Universidade de São Paulo (USP). São Paulo/Brasil. E-mail: apzerbato@gmail.com. ORCID: https://orcid.org/0000-0002-9624-2148

${ }^{3}$ Doutora em Educação Especial pela Universidade Federal de São Carlos (UFSCar). Docente do Instituto Federal de São Paulo (IFSP) e docente colaboradora do Programa de Pós-Graduação em Educação Especial (PPGEEs-UFSCar). São Carlos/São Paulo/ Brasil. E-mail: crios@ifsp.edu.br. ORCID: https://orcid.org/0000-0001-6050-2369

${ }^{4}$ Mestre em Educação Especial pela Universidade Federal de São Carlos. Docente da Educação Especial da Secretaria de Educação do Maranhão (SEDUC/MA) e da Prefeitura Municipal de Caxias. Caxias/Maranhão/Brasil. E-mail: jessicarodr.santos@gmail. com. ORCID: https://orcid.org/0000-0001-9837-901X
} 


\section{INTRODUÇÁo}

Ao analisar as políticas públicas voltadas ao acesso e à permanência de estudantes Público-Alvo da Educação Especial (PAEE) ${ }^{5}$ em cursos técnicos integrados ao Ensino Médio nos Institutos Federais de Educação Ciência e Tecnologia (IFs), até o ano de 2018, constata-se que os IFs têm gradativamente assegurado a oferta de vagas a esse público. Dessa forma, atendem à prerrogativa legal relacionada à garantia do sistema de cotas estabelecido pelo artigo $5^{\circ}$ da Lei no 13.409, de 28 de dezembro de 2016, que incluiu as pessoas com deficiências, decorrente da Lei no 12.711 , de 29 de agosto de 2012. Essa ação pode ser um dos fatores desencadeadores para o acréscimo do número de matrículas de estudantes PAEE nessas instituiçóes de ensino em todo país. Todavia, compreende-se que a garantia do acesso náo compromete diretamente à implementação de políticas educacionais, de âmbito nacional, que oportunizem condiçóes de permanência e de aprendizagem desses estudantes para conclusão do curso nas instituiçốes (Marques, 2014).

Considerando o público e o espaço mencionados, este estudo teve como objetivo geral discutir a atuação do professor de Educação Especial no contexto educacional dos IFs. Para subsidiar a discussão, buscou-se analisar documentos normativos que tratavam da atuação desse professor na Educação Básica de nível Médio Técnico e Tecnológico e suscitar reflexóes sobre a atuação do professor de Educação Especial, traçando um paralelo entre um estudo de caso e os documentos normativos existentes. O estudo foi realizado por meio de açóes metodológicas embasadas na pesquisa documental com abordagem qualitativa.

É pertinente lembrar que as primeiras instituições de ensino técnico no país foram criadas em 1909 pelo então presidente Nilo Peçanha, intituladas "Escolas de Aprendizes Artífices”. Desde então, essas instituiçôes passaram por inúmeras transformaçóes político-educacionais que variaram desde a nomenclatura até o projeto político pedagógico que norteava o ensino. No ano de 2008, quando foram legalmente instituídos os Institutos Federais de Educação, Ciência e Tecnologia (IFs), além da criação de novas unidades, houve a transformação de outras instituiçôes de ensino em Institutos Federais.

Desde 2008, os IFs compóem a maior parte da Rede Federal de Educação Profissional, Científica e Tecnológica (EPCT) do país, sendo, ao todo, 38 institutos, distribuídos pelos 26 estados mais o Distrito Federal, que recebem estudantes PAEE concludentes do Ensino Fundamental e Médio (Domingos Sobrinho, 2013; Schmidt, 2010). A atual organização dos IFs, que comemorou em $2018 \mathrm{dez}$ anos de existência, implementada pela Lei $\mathrm{n}^{\circ} 11.892$, de 29 de dezembro de 2008, define os institutos como "instituiçôes de educação superior, básica e profissional, pluricurriculares e multicampi, especializados na oferta de educaçáo profissional e tecnológica nas diferentes modalidades de ensino, com base na conjugação de conhecimentos técnicos e tecnológicos com as suas práticas pedagógicas”.

De acordo com essa legislação, os IFs são obrigados a respeitar um percentual mínimo de oferta de ensino: $50 \%$ de educação profissional técnica de nível médio, prioritariamente na forma de cursos integrados para os concluintes do Ensino Fundamental e para o público

${ }^{5}$ Considera-se aluno Público-Alvo da Educação Especial: alunos com deficiência, com transtornos globais do desenvolvimento (TGD) e altas habilidades/superdotação (Política Nacional de Educação Especial na Perspectiva da Educação Inclusiva [PNEEPEI], 2008). 
da educação de jovens e adultos, e 20\% de suas vagas para a formação em nível superior de tecnológica, licenciaturas (em especial de exatas), bacharelado em engenharia e pós-graduação lato e stricto sensu (Lei $\left.{ }^{\circ} 11.892,2008\right)$.

No intuito de assegurar políticas de assistência estudantil com foco na permanência, no êxito e no aprendizado dos estudantes, os IFs instituíram núcleos específicos em seus campi, como o Núcleo de Ações Afirmativas (NAAf), o Núcleo de Atendimento às Pessoas com Necessidades Educacionais Específicas (NAPNE), o Núcleo de Estudos Afro-brasileiro e Indígena (NEABI) e o Núcleo de Estudos e Pesquisas em Gênero e Sexualidade (NEPGS). Nem todos os IFs possuem todos os núcleos instaurados, e alguns ainda se encontram em fase de implantação.

O NAPNE é o núcleo responsável pela promoção de ações na maioria dos IFs para o atendimento dos estudantes PAEE, sendo uma das possibilidades de atuação do professor de Educação Especial. O NAPNE foi criado por meio de uma das ações do Programa Educação, Tecnologia e Profissionalização para Pessoas com Necessidades Educacionais Específicas (TEC NEP), que visava, entre suas medidas, a construção de uma política pública inclusiva que oportunizasse "condiçóes de acesso ao público-alvo da Educação Especial nos cursos oferecidos pela Rede Federal de Educação Tecnológica, garantindo-lhes, assim, a inserção no mundo do trabalho e, por conseguinte, independência econômica" (França \& Teixeira, 2016, p. 66).

De acordo com Mendes (2017), é imprecisa a identificação da data exata de criação do primeiro NAPNE, embora afirme ter encontrado orientaçôes acerca da implementação do Núcleo no manual do programa TEC NEP publicado no ano de 2001. Esse processo de implementação do núcleo não ocorreu de forma uniforme e sistemática, como pretendia o Programa TEC NEP, ocasionando algumas diferenças na compreensão do funcionamento do setor entre os diferentes IFs.

Nesse mesmo ano, foi publicada a Resolução CNE/CEB no 2, de 11 de setembro de 2001, que instituiu as Diretrizes Nacionais para a Educação Especial na Educação Básica, trazendo, em seu parágrafo único do artigo $3^{\circ}$, que "Os sistemas de ensino devem constituir e fazer funcionar um setor responsável pela educaçáo especial, dotado de recursos humanos, materiais e financeiros que viabilizem e deem sustentação ao processo de construção da educação inclusiva" (p. 1). O entendimento correlacionado ao "setor responsável pela educação especial" pode ter sido uma das bases que subsidiou a proposta de atuação dos NAPNEs na Rede Federal, quando idealizada.

No que se refere ao público-alvo atendido pelos NAPNEs, não há um consenso entre todos os núcleos: enquanto há NAPNE que atende ao público definido pelo Decreto $\mathrm{n}^{\circ} 7.611$, de 17 de novembro de 2011, há aqueles que assistem a um público mais amplo. Mendes (2017) afirma que os IFs trabalham na perspectiva da educação inclusiva, desenvolvendo açóes que englobam o público determinado pelos documentos normativos brasileiros: pessoas com deficiência, transtornos globais do desenvolvimento (TGD) e altas habilidades/superdotação (AH/ SD), além de pessoas com distúrbios de aprendizagem e idosos em situação de vulnerabilidade educacional. 
As orientaçóes legais para a composição dos NAPNEs apontam que o núcleo pode ser composto por um coordenador e uma equipe multiprofissional, cuja SETEC denominou de "membros". Segundo Waldemar (2012), “os membros desse núcleo são pessoas que se oferecem para auxiliar nas atividades e são efetivados após publicação de portaria pelo reitor do Instituto no qual está inserido o núcleo do qual farão parte” (p. 47). Portanto, quanto a sua composição:

O NAPNE possui um coordenador ${ }^{6}$ que é designado por portaria do Diretor-geral e pode estar apoiado por outros profissionais, como sociólogos, psicólogos, docentes, técnicos e também por alunos bolsistas ou estagiários ou ainda por açóes de voluntariado, inclusive de pais de alunos. (Bortolini, 2012, p. 56)

Identifica-se, contudo, um fator em comum nas duas definiçôes supracitadas, visto que não se menciona o professor de Educação Especial como um profissional especializado na composição desse núcleo. Tal fator implica, portanto, o questionamento: Como é possível o desenvolvimento das açóes que o NAPNE se propóe sem ao menos a institucionalização legal de um profissional especializado no campo da Educação Especial em seu núcleo?

\section{Percursos metodológicos}

Este estudo foi embasado na abordagem qualitativa de pesquisa. Para coleta e tratamento dos dados levantados, fundamentou-se na pesquisa documental. De acordo com Severino (2017), a pesquisa documental, dentre os seus diferentes sentidos, pode ser caracterizada como uma "técnica de identificação, levantamento, exploração de documentos fontes do objeto pesquisado e registro das informações retiradas nessas fontes e que serão utilizadas no desenvolvimento do trabalho" (p. 91).

No caso do presente estudo, foram levantados os documentos oficiais normativos dos Institutos Federais que se referiam ao papel/à atuação da Educação Especial e/ou do professor de Educação Especial nos IFs. Também foram analisados os relatórios que retratavam a atuação de uma professora de Educação Especial em um dos campi do IF Baiano, contrastando e adensando a discussão de como essas legislaçóes têm sido traduzidas nos diferentes contextos da educação profissional e técnica de nível médio e superior.

Assim, o percurso metodológico pode ser descrito da seguinte forma: levantamento das fontes (via sites oficiais dos IFs e por meio de contato via e-mail com profissionais que atuavam nos NAPNEs), leitura minuciosa dos documentos e seleção daqueles que se revelaram importantes para o trabalho. Por último, os documentos foram analisados à luz da literatura específica do campo da Educação Especial sobre o eixo predominante neste trabalho: a atuação do professor de Educação Especial nos Institutos Federais.

\footnotetext{
${ }^{6}$ A maioria dos IFs usa o termo coordenador, mesmo não sendo uma função gratificada. Eles subdividem a composição do núcleo em "coordenador, vice coordenador e secretário". Algumas exceções, como o Instituto Federal São Paulo (IFSP), não trazem essa divisão pela falta de função gratificada e as implicaçóes jurídicas do uso do termo.
} 


\section{Resultados E Discussótes}

Por meio da análise das resoluçóes dos NAPNEs, identificou-se que a maioria dos profissionais com formação em Educação Especial é contratado em regime temporário, isso significa que as instituiçóes aguardam a matrícula dos alunos para posteriormente tomarem providências paliativas para o acolhimento desses estudantes. Mendes (2017) ressalta que "o trabalho ocorre de forma assistemática e descontínua em parte dos IFs, sem a possibilidade de criar condutas institucionais para ao atendimento que venham a se configurar como institucionalizadas" (p. 105).

Ao tomar como base o percurso legal que trata da formação do profissional que trabalhará com o estudante PAEE, a Lei de Diretrizes e Bases da Educação Nacional [LDBEN] - Lei no 9.394, de 20 de dezembro de 1996, em seu capítulo V, que trata da Educação Especial, no artigo 59 - estabelece que os sistemas de ensino devem assegurar aos educandos com necessidades especiais "professores com especialização adequada em nível médio ou superior, para atendimento especializado, bem como professores de ensino regular capacitados para a integração desses educandos nas classes comuns".

A PNEEPEI (2008) pontua que o sistema de ensino deve assegurar a "transversalidade da modalidade de Educação Especial desde a educação infantil até a educação superior”, assim como a oferta do "atendimento educacional especializado" (p. 13). O documento indica que:

Para atuar na educação especial, o professor deve ter como base da sua formação, inicial e continuada, conhecimentos gerais para o exercício da docência e conhecimentos específicos da área. Essa formaçáo possibilita a sua atuação no atendimento educacional especializado, aprofunda o caráter interativo e interdisciplinar da atuação nas salas comuns do ensino regular, nas salas de recursos, nos centros de atendimento educacional especializado, nos núcleos de acessibilidade das instituiçóes de educação superior, nas classes hospitalares e nos ambientes domiciliares, para a oferta dos serviços e recursos de educaçáo especial. (PNEEPEI, 2008, p. 13)

A função docente e a formação para o cargo também são previstas na Resolução do CNE/CEB no 4, de 2 de outubro de 2009, que estabelece as Diretrizes Operacionais para o Atendimento Educacional Especializado (AEE) na Educação Básica e indica que o profissional que atua nesse atendimento "deve ter formação inicial que o habilite para exercício da docência e formação específica para a Educação Especial” (p. 3).

As atribuições ao professor de Educação Especial que irá atuar nesse serviço de apoio à inclusão escolar estão estabelecidas nas Orientaçóes para a Organização de Centros de AEE no Brasil (Nota Técnica - SEESP/GAB/No 9, 2010) e, dentre as diversas funçóes elencadas ao professor de Educação Especial, merece destaque a atribuição que se refere ao estabelecimento da "articulação com os professores da sala de aula comum, visando à disponibilização dos serviços e recursos e o desenvolvimento de atividades para a participação e aprendizagem dos alunos nas atividades escolares" (p. 4).

A Lei Brasileira de Inclusão da Pessoa com Deficiência (LBI ou Estatuto da Pessoa com Deficiência) - Lei no 13.146, de 6 de julho de 2015, quando trata da educação em seu artigo 28, prevê funçóes que compactuam com a proposta aqui apresentada para a atuação desse profissional quando aborda, dentre outras medidas, o que a instituição precisa garantir: 
III - projeto pedagógico que institucionalize o atendimento educacional especializado, assim como os demais serviços e adaptaçóes razoáveis, para atender às características dos estudantes com deficiência e garantir o seu pleno acesso ao currículo em condiçóes de igualdade, promovendo a conquista e o exercício de sua autonomia;

$[\ldots]$

XIII - acesso à educação superior e à educação profissional e tecnológica em igualdade de oportunidades e condiçôes com as demais pessoas;

XIV - inclusão em conteúdos curriculares, em cursos de nível superior e de educaçáo profissional técnica e tecnológica, de temas relacionados à pessoa com deficiência nos respectivos campos de conhecimento. (Lei no 13.146, 2015)

Os destaques aqui apresentados dos documentos normativos brasileiros, referentes à garantia de uma escolarização efetiva para estudantes PAEE, dão subsídios aos institutos federais para a implementação de ações, como a contratação do professor especializado em Educação Especial, para que este contribua no percurso escolar com êxito dos estudantes PAEE matriculados nos IFs.

Dessa forma, portanto, justifica-se a contratação do professor de Educação Especial para realizar, colaborativamente, o AEE, conforme previsto na Lei no 13.530 , de 7 de dezembro de 2017, cujo artigo 9º, inciso XII, prevê a

admissão de profissional de nível superior especializado para atendimento a pessoas com deficiência, nos termos da legislação, matriculadas regularmente em cursos técnicos de nível médio e em cursos de nível superior nas instituiçóes federais de ensino, em ato conjunto do Ministério do Planejamento, Desenvolvimento e Gestão e do Ministério da Educação.

Quanto à formação do educador especial, compreende-se que é possível dois perfis profissionais diferentes: possuir formação inicial de nível superior em Licenciatura em Educação Especial $^{7}$ ou ter uma Licenciatura como formação inicial e formação continuada em nível de pós-graduação em Educação Especial em instituição devidamente registrada no Ministério da Educação.

Para exemplificação da tradução dos documentos normativos analisados referentes à implementação de políticas e ações práticas, destacou-se o IF Baiano que, por meio de planejamento orçamentário, criou um código de vagas para professor de AEE, realizando concurso para contratação de professores efetivos com especialização em Educação Especial (um para cada campi), bem como a criação de vagas para os quadros de Intérprete de Libras e de Revisor de texto em Braille. Apesar da nomenclatura utilizada pela instituição para o cargo ter sido "professor de AEE", entende-se aqui que o AEE é um tipo de serviço de apoio realizado por atividades que não se esgotam na figura do educador especial e que as atribuiçóes desse profissional não se esgotam, nem se resumem, à oferta desse serviço. Dessa forma, não se entende o cargo de professor de AEE como sinônimo de professor de Educação Especial.

\footnotetext{
${ }^{7}$ Até a conclusão deste estudo, somente a Universidade Federal de Santa Maria (RS) e a Universidade Federal de São Carlos (SP) ofertavam o curso de formação inicial em Educação Especial de forma presencial na rede pública de Ensino Superior, porém existem diversas instituiçóes particulares que ofertam o curso de forma presencial e no formato EaD.
} 
Além do IF Baiano, registra-se que os seguintes IFs contam com professores de Educação Especial em seus quadros: Instituto Federal do Amapá (IFAP) ${ }^{8}$, Instituto Federal Catarinense (IFC) ${ }^{9}$, Instituto Federal de Santa Catarina (IFSC) ${ }^{10}$, Instituto Federal de Farroupilha (IFFarroupilha) ${ }^{11}$ e, mais recentemente, o Instituto Federal do Paraná (IFPR) ${ }^{12}$. Em todas as instituiçóes citadas, os profissionais foram ou serão contratados com o cargo de professor do Ensino Básico, Técnico e Tecnológico, reforçando o entendimento de que a Educação Especial é uma modalidade de ensino; logo, requer a necessidade de um professor(a) com habilidades nesse campo de conhecimento.

Outro fator que fomenta a importância da contratação de professores de Educação Especial nos IFs é o fato de que, por se tratar de uma instituição que atua no ensino de nível médio integrado ao Ensino Técnico e Tecnológico, alguns dos professores que compóem o quadro, em especial os que lecionam nos cursos técnicos, não são formados em cursos de licenciatura, visto que possuem formaçôes em bacharelado e aprendem a ser professores na prática. Esse desafio da docência, após o concurso público, traz reflexões sobre a formação no campo pedagógico e sobre a inexistência da discussão sobre o estudante PAEE na formação inicial de alguns cursos, por exemplo os bacharelados. Vale ressaltar que não existem pesquisas concluídas até o momento que analisaram como esses profissionais têm atuado nessas instituiçóes, quais os graus de colaboração com os demais profissionais e até para a própria realização do AEE.

O IF Baiano, por meio do seu Regulamento do AEE (Resolução no 19, de 18 de março de 2019), apresenta uma proposta de atividades que contempla oferecer o AEE por meio de recursos educacionais, estratégias de apoio, suplementação e complementação do ensino para os estudantes que compóem o PAEE nos Institutos Federais. Nessa instituição, entende-se que o professor de AEE, Educador Especial, em parceria com os demais profissionais, seria o responsável pelas atividades. As açóes do AEE têm como base as necessidades educacionais de cada estudante, tendo o profissional que atua nesse serviço as seguintes atribuições na instituição:

Artigo $4^{\circ}$ São objetivos do AEE:

I - atuar e contribuir com a consolidação de políticas públicas para a inclusáo e para a diversidade no IF Baiano;

II- atuar e contribuir com a eliminação de barreiras arquitetônicas, comunicacionais, metodológicas, instrumentais, programáticas e atitudinais, buscando a adaptação dos espaços acadêmicos às necessidades dos estudantes;

III - acompanhar e orientar os estudantes Público-Alvo do Atendimento Educacional Especializado (PAEE), individual ou coletivamente, em atividades nas SRM e no ensino colaborativo, com os docentes dos componentes curriculares de cursos de todos os níveis e modalidades do IF Baiano, de forma a contribuir com a apropriação do conhecimento pelo estudante;

\footnotetext{
${ }^{8}$ Ver Edital no01/2013, http://siteantigo.ifap.edu.br/index.php?option=com_content\&view=article\&id=959\%3Aifap-lanca-concurso-publico-com-35-vagas-para-professor-do-quadro-permanente\&catid=1\%3Aultimas \&Itemid=1;

e Edital no 1/2019, http://portal.ifap.edu.br/index.php/publicacoes/item/2360-edital-n-1-2019-retificado, http://portal.ifap.edu. br/index.php/publicacoes/item/2360-edital-n-1-2019-retificado

${ }^{9}$ Cargo instituído pela Portaria Normativa n ${ }^{\circ}$, de 29 de janeiro de 2018.

${ }^{10}$ Ver Edital no 33/2017, https://www.iffarroupilha.edu.br/concursos-encerrados/item/7382-docentes-concurso-realizado-em-2013

${ }^{11}$ Ver Edital no 304/2013, http://w2.iffarroupilha.edu.br/site/midias/arquivos/20131127204536660edital_n\%C2\%BA_304.2013_-_ concurso_publico_docentes.pdf

${ }^{12}$ Ver Edital n 8, de 21 de maio de 2019, http:/www.in.gov.br/web/dou/-/edital-n-8-de-21-de-maio-de-2019-concurso-publico-para-provimento-de-cargos-de-professor-da-carreira-de-magisterio-do-ensino-basico-tecnico-e-tecnologico-educacao-especial-118516711
} 
IV - orientar os docentes do ensino comum quanto à seleção, à adaptação e à utilização dos recursos, dos materiais e das estratégias pedagógicas, participando do planejamento e da avaliação das aulas e das atividades;

$\mathrm{V}$ - apontar as ações estratégicas ao atendimento das necessidades dos estudantes PAEE, em parceria com o NAPNE, como a aquisição de equipamentos, a adaptação dos espaços e do transporte, entre outras;

VI - promover a participação da comunidade escolar, da família ou dos responsáveis pelos estudantes PAEE, sensibilizando-os sobre as suas condiçóes de acesso, de participação e de aprendizagem, a fim de propiciar condições de permanência, de conclusão e de continuidade dos estudos. (Resolução no 19, 2019, p. 9-10).

Entende-se que a configuraçáo do AEE, no contexto dos IFs, possui particularidades, se comparada à Educação Básica da rede municipal e estadual ou às instituições de Ensino Superior por atuarem nos diferentes níveis. Os relatos sobre a atuação desse profissional são escassos, visto que essa função assumida em alguns institutos é recente, mas podem ser ilustrados no relato de experiência apresentado a seguir.

\subsection{Atuaçáo do professor de EducaÇão Especial em um dos Campi do Instituto Federal Baiano}

Segundo o Plano de Desenvolvimento Institucional (2015-2019) do Instituto Federal Baiano, a instituição inicia sua história na cidade de Catu, com a oferta de ensino profissional na área agrária da Bahia, em 1897. Sua expansão aconteceu gradativamente em diversos municípios baianos e, hoje, integra, ao todo, 14 campi. Mais especificamente, no sul da Bahia, a expansão dos IFs deve-se à integração, no ano de 2010, das antigas Escolas Médias de Agropecuária Regional (EMARC), mantidas pela Comissão Executiva do Plano da Lavoura Cacaueira (CEPLAC), órgão vinculado ao Ministério da Agricultura. O campus de UruçucaBA, por exemplo, é uma dessas escolas que, por meio do Decreto ${ }^{\circ} 7.952$, de 12 de março de 2013, foi vinculada definitivamente às EMARCs do Ministério de Educação, transformando-as em campus do IF Baiano.

No ano de 2018, o campus de Uruçuca atuava com dois cursos técnicos integrados ao Ensino Médio (Informática e Guia de Turismo) e três cursos técnicos subsequentes ao Ensino Médio (Técnico em Alimentos, Agropecuária e Agrimensura), além de três cursos superiores em tecnólogo em Agroecologia e Gestáo de Turismo, e um bacharelado em Engenharia de Alimentos. Possuía três núcleos implementados para o desenvolvimento das Políticas de Diversidade e Inclusão ${ }^{13}$ : o NEABI, o Núcleo de Estudos de Gênero e Sexualidade (GENI) e o NAPNE.

O NAPNE do IF Baiano, campus de Uruçuca, foi implementado em 2015 e era composto por um profissional intérprete de língua de sinais, um psicólogo, uma assistente social, uma assistente de alunos e um docente do campus. Como se pretende discutir o papel do AEE a partir da entrada do profissional da Educação Especial na equipe, o foco será na estrutura e nas açóes do núcleo no contexto de 2018 para fundamentação das discussóes aqui pretendidas.

${ }^{13}$ Ver http://www.ifbaiano.edu.br/unidades/urucuca/ 
Assim, no ano de 2018, o NAPNE do IF Baiano, campus de Uruçuca, estava constituído pelos seguintes membros: dois tradutores intérpretes de língua de sinais, um revisor de texto Braile, um professor de Educação Especial, uma assistente de alunos ${ }^{14}$, um professor da área da Letras-Libras, um pedagogo, um psicólogo, uma técnica da área da informática e quatro docentes das áreas comuns de ensino. Além desses, havia uma profissional técnica da área da saúde, contratada ${ }^{15}$ como cuidadora naquele ano para dar suporte a dois estudantes específicos. A Tabela 1 apresenta a relaçáo de estudantes atendidos pelo NAPNE, campus de Uruçuca, no ano de 2018, e os profissionais do núcleo que davam suporte a esses estudantes.

Após encaminhamento, que poderia ser realizado por um professor, profissional, familiar ou pelo próprio estudante que solicita o atendimento, os estudantes eram ouvidos e avaliados por, pelo menos, dois membros do NAPNE (coordenação que recebia a ficha de encaminhamento e o professor de Educação Especial ou coordenação e o psicólogo ou coordenação e assistente social, de acordo com a solicitação encaminhada) para definição dos suportes necessários de acordo com suas demandas e especificidades. Os estudantes passavam por avaliação pedagógica para identificação dos apoios necessários. Quando esses estudantes não possuíam uma demanda de atendimento educacional, os membros do NAPNE os encaminhavam para outros setores, como o de saúde ou de assistência social, para um atendimento especializado para a demanda reconhecida.

Quando era identificado pelos membros do núcleo que o apoio ao estudante se tratava do serviço ofertado pelo NAPNE, os membros discutiam as estratégias e os recursos que poderiam viabilizar sua efetiva escolarização no Ensino Médio e/ou Técnico. Por tratar-se de uma atuação inédita e de um público com necessidade de apoios específicos, as ações para o apoio do Educador Especial eram discutidas e construídas de acordo com o contexto educacional. Esse entendimento parte do pressuposto de que nem todos os alunos atendidos pelo NAPNE deveriam ou necessitariam de apoio do educador especial.

Exemplos desses casos foram os estudantes que apresentaram necessidades específicas, mas não eram PAEE, como Tales (18a), diagnosticado com Transtorno de Déficit de Atenção, que cursava o Ensino Médio integrado Guia de Turismo (2ªno) e Jonas (23a), estudante com Dislexia, que cursava o Ensino Superior em Gestão de Turismo (4o semestre). Ambos recebiam apoio educacional do Psicopedagogo. O NAPNE também atuou em casos como o de Janaina (28a), sem diagnóstico, do curso Técnico em Agropecuária (com várias reprovaçóes em disciplinas), que era acompanhada pelo Pedagogo e Psicopedagogo do campus (Zerbato \& Oliveira, 2018). Também havia estudantes PAEE que, mesmo sendo o público de atuação do educador especial, em reunióes do núcleo, entendeu-se que eles não necessitariam de um apoio direto do educador especial (ver Quadro 1).

\footnotetext{
${ }^{14}$ Devido à formação da Assistente de Alunos em Psicopedagogia, a profissional tem colaborado com o NAPNE em sua área de conhecimento.

${ }^{15}$ Contratada via empresa terceirizada.
} 


\section{Quadro 1}

Apoios para estudantes atendidos pelo NAPNE

\begin{tabular}{|l|l|}
\hline Estudante / Idade/Especificidades / Curso/Semestre & Profissionais de apoio - Atuação \\
\hline $\begin{array}{l}\text { Ivan (21a) - Deficiência Física - Superior em Gestão de } \\
\text { Turismo (2o semestre). }\end{array}$ & $\begin{array}{l}\text { Coordenação do NAPNE para orientaçóes de auxílio } \\
\text { e outros. }\end{array}$ \\
\hline $\begin{array}{l}\text { Leonardo (25a) - Amputação da perna direita - Supe- } \\
\text { rior em Gestão de Turismo (20 semestre). }\end{array}$ & $\begin{array}{l}\text { Coordenação do NAPNE para orientaçóes de auxílio } \\
\text { e outros. }\end{array}$ \\
\hline $\begin{array}{l}\text { Adriana (29a) - Surdez leve do ouvido direito; Curso } \\
\text { Técnico em Alimentos (30 semestre). }\end{array}$ & $\begin{array}{l}\text { Coordenação do NAPNE caso necessite de alguma } \\
\text { orientação. }\end{array}$ \\
\hline $\begin{array}{l}\text { Rogério (28a) - Artrogripose congênita - Curso Técni- } \\
\text { co em Agrimensura (3o semestre). }\end{array}$ & $\begin{array}{l}\text { Cuidador para o uso do banheiro e refeitório; } \\
\text { Coordenação do NAPNE para orientaçóes gerais ao } \\
\text { discente. }\end{array}$ \\
\hline
\end{tabular}

Nota. Os nomes são fictícios para manutenção da identidade dos estudantes. Adaptada de Zerbato \& Oliveira (2018).

Mesmo os casos que não recebiam apoio direto do professor de Educação Especial, ressalta-se a importância e a colaboração desse profissional no contexto das avaliaçóes institucionais, discussóes dos casos nas reuniōes do NAPNE e nas reunióes pedagógicas dos cursos, bem como nas parcerias com os demais profissionais.

\section{Quadro 2}

Apoios para estudantes atendidos pelo NAPNE e exemplo da atuação do professor de Educação Especial

\begin{tabular}{|c|c|c|}
\hline $\begin{array}{l}\text { Estudante / Especificidades Idade/ } \\
\text { Curso/Semestre }\end{array}$ & Profissionais de apoio & $\begin{array}{l}\text { Açóes desenvolvidas pela professora de Educação } \\
\text { Especial }^{16}\end{array}$ \\
\hline $\begin{array}{l}\text { Daniela }(27 a) \text { - Surdez - Curso Téc- } \\
\left.\text { nico em Alimentos ( } 3^{\circ} \text { semestre }\right) \text {. }\end{array}$ & $\begin{array}{l}\text { Tradutores-intérpretes; } \\
\text { Professor de Educação } \\
\text { Especial; Psicólogo }\end{array}$ & $\begin{array}{l}\text { Ensino da língua portuguesa na modalidade escrita, } \\
\text { como segunda língua; } \\
\text { Atendimento individualizado para acompanhamento } \\
\text { e realização de tarefas acadêmicas } \\
\text { Orientaçáo aos docentes, em parceria com o intérpre- } \\
\text { te, para elaboração de materiais visuais de apoio ao } \\
\text { aprendizado }\end{array}$ \\
\hline $\begin{array}{l}\text { Douglas (26a) - Cegueira total no } \\
\text { olho direito - Superior em Gestâo de } \\
\text { Turismo ( } 2^{\circ} \text { semestre). }\end{array}$ & $\begin{array}{l}\text { Professor de Educação } \\
\text { Especial; revisor de texto } \\
\text { Braille; Coordenação do } \\
\text { NAPNE }\end{array}$ & $\begin{array}{l}\text { Adaptação de materiais de estudo; } \\
\text { Ampliação de textos; } \\
\text { Orientaçóes aos docentes para melhorias do ensino }\end{array}$ \\
\hline $\begin{array}{l}\text { Rafael (30a) - Deficiência Visual; } \\
\text { Ansiedade Generalizada - Superior } \\
\text { em Gestão de Turismo (Disciplinas } \\
\text { pendentes). }\end{array}$ & $\begin{array}{l}\text { Professor de Educação } \\
\text { Especial; Revisor de texto } \\
\text { Braille; Psicólogo; Assis- } \\
\text { tente social }\end{array}$ & $\begin{array}{l}\text { Adaptação de materiais } \\
\text { Atendimento individualizado para acompanhamento } \\
\text { e realização de tarefas acadêmicas; } \\
\text { Orientaçóes aos docentes para melhorias nas aulas }\end{array}$ \\
\hline $\begin{array}{l}\text { Tereza }(25 a) \text { - Deficiência Visual, } \\
\text { Ambliopia- } \\
\text { Engenharia de Alimentos ( } 1^{\circ} \\
\text { semestre). }\end{array}$ & $\begin{array}{l}\text { Professor de Educação } \\
\text { Especial; revisor de texto } \\
\text { Braille; Coordenação do } \\
\text { NAPNE }\end{array}$ & $\begin{array}{l}\text { Adaptaçóes de materiais e do espaço físico para me- } \\
\text { lhor aproveitamento das aulas; } \\
\text { Orientaçóes aos docentes para melhorias do ensino }\end{array}$ \\
\hline
\end{tabular}

16 As normativas do IF Baiano nomeiam o cargo como "Professor de AEE", porém utilizou-se a nomeação Educador Especial pela descrição desse profissional na instituição e o entendimento do AEE descrito neste artigo. 


\begin{tabular}{|c|c|c|}
\hline $\begin{array}{l}\text { Hugo (18a) - Deficiência Física: } \\
\text { incoordenação motora e dificuldades } \\
\text { na fala - Curso Técnico em Alimen- } \\
\text { tos ( } 2^{\circ} \text { semestre). }\end{array}$ & $\begin{array}{l}\text { Professor de Educaçãoo } \\
\text { Especial }\end{array}$ & $\begin{array}{l}\text { Atendimento individualizado para acompanhamento } \\
\text { e realização de tarefas acadêmicas. } \\
\text { Acompanhamento das aulas práticas para dar suporte } \\
\text { ao estudante } \\
\text { Orientaçóes aos docentes para melhorias nas aulas } \\
\text { Adaptaçôes de materiais e provisão de Tecnologia } \\
\text { Assistiva }\end{array}$ \\
\hline $\begin{array}{l}\text { Deise (20a) - Deficiência física: na- } \\
\text { nismo - Curso Técnico em Alimentos } \\
\text { (1º semestre). }\end{array}$ & $\begin{array}{l}\text { Professor de Educaçãao } \\
\text { Especial; coordenação do } \\
\text { NAPNE }\end{array}$ & $\begin{array}{l}\text { Orientações sobre adaptação de materiais e mobili- } \\
\text { ário; } \\
\text { Orientações aos docentes para melhorias nas aulas }\end{array}$ \\
\hline $\begin{array}{l}\text { Junior }(25 a) \text { - Surdez - Curso Técni- } \\
\left.\text { co em Alimentos ( } 2^{\circ} \text { semestre }\right) \text {. }\end{array}$ & $\begin{array}{l}\text { Tradutores-intérpretes; } \\
\text { Professor de Educação } \\
\text { Especial; Professor de L2 }\end{array}$ & $\begin{array}{l}\text { Ensino da língua portuguesa na modalidade escrita } \\
\text { como segunda língua (em parceria com o professor } \\
\text { de L2); } \\
\text { Atendimento individualizado para acompanhamento } \\
\text { e realização de tarefas acadêmicas; } \\
\text { Orientação aos docentes, em parceria com o intérpre- } \\
\text { te, para elaboração de materiais visuais de apoio ao } \\
\text { aprendizado }\end{array}$ \\
\hline $\begin{array}{l}\text { Marcelo (27a) - Paralisia Cerebral } \\
\text { - Curso Técnico em Alimentos ( } 1^{\circ} \\
\text { semestre). }\end{array}$ & $\begin{array}{l}\text { Professor de Educação } \\
\text { Especial; Cuidador }\end{array}$ & $\begin{array}{l}\text { Atendimento individualizado para acompanhamento } \\
\text { e realizaçáo de tarefas acadêmicas; } \\
\text { Acompanhamento das aulas teóricas para dar suporte } \\
\text { ao estudante; } \\
\text { Orientaçóes aos docentes para melhorias nas aulas }\end{array}$ \\
\hline $\begin{array}{l}\text { Jorge (30a) - Deficiência Visual - } \\
\text { Curso Técnico em Agropecuária (2o } \\
\text { semestre). }\end{array}$ & $\begin{array}{l}\text { Professor de Educação } \\
\text { Especial; revisor de texto } \\
\text { Braille; Coordenação do } \\
\text { NAPNE }\end{array}$ & $\begin{array}{l}\text { Adaptaçóes de materiais e do espaço físico para me- } \\
\text { lhor aproveitamento das aulas; } \\
\text { Orientaçóes aos docentes para melhorias do ensino }\end{array}$ \\
\hline $\begin{array}{l}\text { Roberto (28a) - Surdez - Curso Téc- } \\
\text { nico em Agropecuária ( } 3^{\circ} \text { semestre). }\end{array}$ & $\begin{array}{l}\text { Tradutores - intérpretes; } \\
\text { Professor de Educação } \\
\text { Especial; professor de L2 }\end{array}$ & $\begin{array}{l}\text { Ensino da língua portuguesa na modalidade escrita } \\
\text { como segunda língua (em parceria com o professor } \\
\text { de L2); } \\
\text { Atendimento individualizado para acompanhamento } \\
\text { e realização de tarefas acadêmicas } \\
\text { Orientação aos docentes, em parceria com o intérpre- } \\
\text { te, para elaboraçáo de materiais visuais de apoio ao } \\
\text { aprendizado }\end{array}$ \\
\hline $\begin{array}{l}\text { Gustavo (40a) - Sem diagnóstico; } \\
\text { Suspeita de deficiência intelectual } \\
\text { Técnico em Agrimensura ( } 3^{\circ} \text { semes- } \\
\text { tre - Dependências). }\end{array}$ & $\begin{array}{l}\text { Professor de Educação } \\
\text { Especial; Psicólogo; Assis- } \\
\text { tente Social }\end{array}$ & $\begin{array}{l}\text { Atendimento individualizado para acompanhamento } \\
\text { e realização de tarefas acadêmicas; } \\
\text { Acompanhamento e observaçáo das aulas visando arti- } \\
\text { culação colaborativa com os docentes para proposição } \\
\text { de estratégias; } \\
\text { Orientaçôes aos docentes para melhorias nas aulas; } \\
\text { Discussóes de propostas nas reunióes de conselho de } \\
\text { curso com toda equipe pedagógica e docentes }\end{array}$ \\
\hline $\begin{array}{l}\text { Vitor }(17 \mathrm{a}) \text { - Síndrome de Asperger } \\
\text { - Ensino Médio integrado em Infor- } \\
\text { mática ( } 3^{\circ} \text { ano). }\end{array}$ & $\begin{array}{l}\text { Professor de Educação } \\
\text { Especial }\end{array}$ & $\begin{array}{l}\text { Acompanhamento e observação das aulas visando arti- } \\
\text { culaçáo colaborativa com os docentes para proposiçáo } \\
\text { de estratégias; } \\
\text { Orientaçôes aos docentes para melhorias nas aulas }\end{array}$ \\
\hline $\begin{array}{l}\text { João (21a) - Dislexia- Ensino Médio } \\
\text { integrado em Informática ( } 3^{\circ} \text { ano). }\end{array}$ & $\begin{array}{l}\text { Professor de Educação } \\
\text { Especial; Psicopedagogo }\end{array}$ & $\begin{array}{l}\text { Acompanhamento e observação das aulas visando arti- } \\
\text { culação colaborativa com os docentes para proposiçáo } \\
\text { de estratégias; } \\
\text { Orientaçôes aos docentes para melhorias nas aulas }\end{array}$ \\
\hline
\end{tabular}

Nota. Os nomes são fictícios para manutenção da identidade dos estudantes. Os dados "estudante/especificidades idade/curso/semestre/" e "profissionais de apoio" são de Zerbato \& Oliveira (2018).

Zerbato e Oliveira (2018) realizaram pontuações sobre as atribuições do educador especial. Para as autoras, essa atuação diferenciava-se de acordo com a demanda específica de cada estudante e podiam ser: i) atendimentos individualizados no contraturno e acompanhamentos 
pontuais do professor de Educação Especial em sala de aula comum na perspectiva de atuação colaborativa com o professor do ensino comum; ii) atendimento na perspectiva do ensino colaborativo em sala de aula para apoio do professor do ensino comum; iii) participação em reunióes pedagógicas; iv) momentos formativos aos professores que atendem a esses estudantes; v) participação em reuniōes de conselho; vi) elaboração de materiais e adaptação de avaliaçóes; vii) AEE para o ensino do português escrito para estudantes surdos; e viii) AEE em Libras para estudantes surdos para realizaçáo de atividades complementares de ensino.

O campus de Uruçuca, em 2018, apresentava um número significativo de estudantes PAEE com diversas demandas educacionais e sociais. Verifica-se que a implementação de um núcleo que dê suporte a esses estudantes e viabilize a efetivação do AEE são de extrema relevância, porém não solucionará sozinho os desafios que a educação inclusiva apresenta.

A constituição da rede de apoios composta pelos próprios profissionais que integravam o NAPNE, no campus analisado, era recente, por isso não foram encontrados resultados de médio e longo prazo das açóes realizadas. A análise a curto prazo da ação pode apontar uma estratégia efetiva na construção da cultura colaborativa e da inclusão escolar na instituição, considerando-se algo favorável ao fortalecimento e à ampliação dos suportes ofertados ao público atendido pelo núcleo. A soma de conhecimentos e práticas dos diferentes profissionais que compunham a equipe de apoio foi muito importante na tomada de decisões e elaboração de estratégias junto aos professores do ensino comum a favor do aprendizado dos estudantes PAEE.

Em relação à implementação do AEE na instituição analisada, o desafio foi enorme, pois tratava-se de um ambiente educacional diferente da Educação Básica, referente à Educação Infantil e ao Ensino Fundamental, com utilização de tempo integral de ensino. Ademais, a maneira como os documentos normativos e as políticas de inclusão no âmbito nacional para a Educação Básica apontam a atuação do docente da Educação Especial em uma Sala de Recursos Multifuncionais (SRM) engessa a realização do AEE e dificulta sua efetividade, pois o profissional que trabalha dentro de uma SRM, em período contrário ao da escolarização do estudante PAEE, diminui suas chances de entender e contribuir com o contexto mais importante no processo de aprendizado desse aluno: a sala de aula comum.

No contexto analisado, muitos cursos eram integrais, inviabilizando a proposta do AEE em SRM. Assim, outras propostas têm sido realizadas e experimentadas, como o AEE no modelo do Ensino Colaborativo.

O ensino colaborativo ou coensino é um dos modelos de prestação de serviço de apoio no qual um professor comum e um professor especializado dividem a responsabilidade de planejar, instruir e avaliar o ensino dado a um grupo heterogêneo de estudantes. Tal modelo emergiu como alternativa aos modelos de sala de recursos, classes especiais ou escolas especiais, especificadamente para responder às demandas das práticas de inclusão escolar de estudantes do público-alvo da educação especial [...]. (Mendes et al., 2014, p. 45)

Ainda se trata de uma proposta recente, mas já vem sendo discutida com os profissionais da instituição e incluída no regimento do AEE - Resolução no 19/2019 do Instituto Federal Baiano, a fim de que essa e outras possibilidades de serviço de apoio possam estar embasadas oficialmente. Além disso, verificou-se, no curto período de implementação do AEE, 
a necessidade de enfrentamento a algumas dificuldades, como as relacionadas: ao insuficiente quantitativo de profissionais para o atendimento de todas as demandas do campus; à escassez de recursos para maior investimento em recursos humanos e materiais; bem como ao desafio em se pensar em implementar ações formativas que possibilitem aos docentes a revisão de suas estratégias didáticas e metodológicas de ensino para a melhoria do ensino a todos.

Zerbato e Oliveira (2018) identificaram as seguintes demandas para aperfeiçoamento e construção de um ensino mais inclusivo na instituição apresentada: i) criação de vagas e contratação de profissionais especializados para trabalho em rede, como fonoaudiólogo, terapeuta ocupacional, psicopedagogo, entre outros; ii) ampliaçáo do quadro de tradutores intérpretes da língua de sinais de acordo com a demanda do campus e em consonância com as normas de trabalho do profissional; e iii) investimento em formaçóes, iniciais e continuadas, que respondam às demandas internas e atinjam a comunidade externa em que a instituição está inserida.

Existe a necessidade também da construção do trabalho no modelo do ensino colaborativo ou coensino nas turmas que tenham estudantes PAEE matriculados, sempre que a avaliação prévia desse estudante apontar essa necessidade, depois se entende ser uma alternativa de trabalho efetiva para organizar o ensino dos estudantes PAEE e demais em sala de aula do ensino comum.

É preciso ter garantia, no horário de trabalho docente, de momentos de planejamento em conjunto entre professor de Educação Especial e professor dos componentes curriculares comuns. Para Argueles et al. (2000), a prática efetiva do ensino colaborativo demanda um tempo de planejamento em conjunto para compartilhamento e discussão de ideias, principalmente se o professor de Educação Especial náo fica o tempo todo em sala de aula com o professor de ensino comum. Desse modo, possibilita-se que o professor de Educação Especial compreenda como está o andamento do trabalho em sala de aula quando não está presente e lhe dá a oportunidade de sugerir adaptaçóes e estratégias para o ensino dos estudantes PAEE. Nas reuniōes de planejamento, os professores têm a oportunidade de refletirem sobre suas aulas diárias, sobre a elaboração de um Planejamento Educacional Individualizado (PEI) ${ }^{17}$ e definir papéis e responsabilidades do trabalho em conjunto antes, durante e após a aula.

Ressalta-se a importância dos momentos de diálogo para reflexão e elaboração das adaptaçóes curriculares quando necessário e garantir estratégias, como disponibilização de maior tempo para realização das disciplinas e do curso, tempo estendido para realização de uma avaliação, presença de um profissional ledor para uma atividade quando necessário, entre outras. Nesse ponto, ressalta-se que é importante que essas adaptaçóes do currículo estejam inseridas no PEI do estudante e nos documentos oficiais que regem o ensino da instituição, a fim de garantir estratégias que visam a permanência e a conclusão do curso por parte do estudante PAEE, como a certificação diferenciada, quando ela se fizer necessária.

Ademais, garantir momentos para debate e produção de novas estratégias de ensino em sala de aula comum. Destaca-se que a participação em momentos formativos em serviço é fundamental aos docentes para que ultrapassem as práticas mais tradicionais excludentes e se lancem

17 “O PEI é um documento que requer avaliação prévia e criteriosa bem como debate entre todos aqueles que convivem com o aluno PAEE, inclusive com ele próprio na busca pela definição dos caminhos necessários para sua aprendizagem" (Santos \& Vilaronga, 2019, p. 10). 
em estratégias mais coletivas e mais dialógicas, de acordo com as especificidades dos seus estudantes, como a tutoria de pares, o reconhecimento da melhor forma que cada estudante apresenta a resposta esperada em relação ao que aprendeu, a elaboração de práticas pautadas no Desenho Universal para a Aprendizagem (DUA), o uso de Tecnologia Assistiva (TA), entre outras.

A implantação da cultura colaborativa e inclusiva na instituição faz-se necessária para que todos os atores tenham clareza sobre os objetivos da instituição de ensino e qual o papel de cada profissional, pois "na ausência da implementação de políticas públicas atrelada [à] falta de uma discussão aprofundada que envolva comunidade interna e externa, os princípios inclusivos acabam se tornando frágeis e o processo educacional inclusivo vulnerável” (Zerbato \& Oliveira, 2018, p. 13).

Nesse curto período de inserção de novos profissionais no IF Baiano para benefício da inclusão escolar da instituição, constatou-se que a implementação do AEE faz parte dos esforços em garantir os direitos e os suportes necessários aos estudantes PAEE da rede de educação profissional e tecnológica. Reconhece-se que a atuação do docente de Educação Especial suscitou, no contexto analisado, discussóes sobre o modelo único de atuação que a PNEEPEI (2008) propóe, pois constata-se que não é possível conceber o AEE apenas em SRM. Desse modo, outras formas de potencializar-se o AEE no Instituto Federal Baiano apresentaram-se como necessárias, e o ensino colaborativo foi um exemplo disso.

\section{Conclusóes}

Considerando os documentos normativos apresentados e analisados, bem como as pontuaçóes sobre a ação do professor de Educação Especial identificadas no exemplo analisado, entendeu-se que assegurar apenas o ingresso do estudante PAEE, por meio da matrícula comum ou pelo sistema de cotas (Lei no 12.711, 2012) nos IFs, não é suficiente para promover a inclusão escolar nesses espaços, pois não garante a implementação de ações previstas em lei, nem mesmo a equidade nos processos de ensino e de aprendizagem.

No caso dos estudantes PAEE, a legislação brasileira prevê a oferta do AEE como o diferencial para garantia ao direito à escolarização plena. Logo, esse diferencial implica diretamente na necessidade da existência do cargo de professor especialista em Educação Especial para execução das atribuições inerentes ao seu trabalho.

A apresentação da ação conjunta entre professor de Educação Especial, membros do NAPNE e demais profissionais do campus do IF Baiano demonstrou que a atuação desse professor é essencial nesse contexto. Defende-se, portanto, que se faz necessária a implementação de uma normativa específica por parte da Secretaria de Modalidades Especializadas na Educação (SEMESP) ${ }^{18}$, possibilitando que os IFs possam abrir concurso público para docentes especialistas na área da Educação Especial, tendo em vista que os regulamentos de composição dos NAPNEs apontam que esse profissional quase nunca compóe o quadro de funcionários e, quando o faz, é em caráter temporário, com algumas exceçóes.

Os NAPNEs têm desempenhado um papel fundamental nos IFs, mas não têm conseguido, principalmente após o aumento do número de estudantes PAEE, atender a todos os

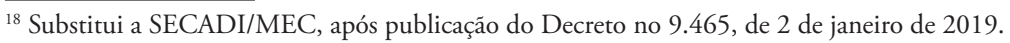


objetivos que se propõe, em especial por, muitas vezes, não possuírem profissionais com formação específica para oportunizar discussóes dentro dos campi.

Entende-se a importância dos demais profissionais do quadro de servidores atuarem para garantir o processo da inclusão escolar e que estes necessitam agir de maneira articulada no atendimento desses estudantes, mas ressalta-se que a existência desses profissionais não exime a responsabilidade da instituição em ter em seu quadro de servidores o profissional com formação específica em Educação Especial. Pensar em inclusão escolar ou, no mínimo, em "adaptações razoáveis", só é possível por meio de ações coletivas entre diferentes profissionais, sendo necessário, portanto, para a efetivação de uma ação colaborativa nos IFs, a presença do educador especial.

Destacam-se, ainda, as diferentes realidades presentes nos inúmeros institutos. Enquanto o IF Baiano, após o ingresso do Professor de Educação Especial, buscou estratégias para melhorar a qualidade do serviço ofertado e lutar pela construçáo da cultura colaborativa na instituição, muitos IFs lutam ainda para conseguir a regularização do cargo de Professor de Educação Especial. Esse é o caso do Instituto Federal de São Paulo (IFSP), no qual o Atendimento Educacional Especializado aparece no Plano de Desenvolvimento Institucional (2019-2023) ${ }^{19}$ da instituição como uma das atribuições do NAPNE, como ação de acompanhamento e de permanência dos estudantes do IFSP. Entretanto, no instituto, ainda não existe a previsão de concurso específico para contratação de profissional especializado para atuar com o AEE.

Com a problematização das linhas organizadoras de apoio e com o exemplo de um contexto específico relativo à instituição analisada, espera-se que este estudo fomente a discussão sobre a atuação do Educador Especial em contexto dos IFs. Todavia, considera-se que o eixo analisado é promissor para o desenvolvimento de novos estudos e debates sobre o tema. Sugerem-se, assim, pesquisas futuras que enfoquem estudos de casos de estudantes atendidos pelo educador especial, que analisem a atuação de forma aprofundada e descreva a prática desse profissional. Além disso, que se pesquisem práticas vivenciadas por outras instituiçóes com características semelhantes à analisada, mas que apresentem atuaçóes diferentes, entre outras lacunas de investigação sobre o tema.

\section{REFERÊNCIAS}

Arguelles, M. E., Hugles, M. T., \& Schumm, J. S. (2000). Co-teaching: a different approach to inclusion. Principal Reston, 79(4), 48-50.

Bortolini, S. (2012). Desafios e estratégias para tornar o IFRS - Campus Bento Gonçalves uma escola inclusiva [Dissertação de Mestrado, Universidade Federal Rural do Rio de Janeiro]. Sistema de Publicação Eletrônica da Universidade Federal Rural do Rio de Janeiro. http://cursos.ufrrj.br/posgraduacao/ ppgea/files/2015/10/Sirlei-Bortolini.pdf

Decreto ${ }^{\circ} 7.952$, de 12 de março de 2013. Dispóe sobre a vinculação das Escolas Médias de Agropecuária Regional ao Ministério da Educação. Presidência da República/Casa Civil. http://www.planalto. gov.br/CCIVIL_03/_Ato2011-2014/2013/Decreto/D7952.htm

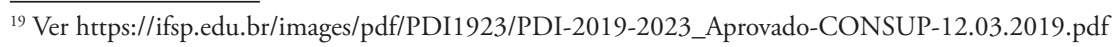


Decreto $\mathrm{n}^{\circ}$ 7.611, de 17 de novembro de 2011. Dispóe sobre a educação especial, o atendimento educacional especializado e dá outras providências. https://bit.ly/36xbhjD

Decreto $\mathrm{n}^{\circ}$ 9.465, de 2 de janeiro de 2019. Aprova a Estrutura Regimental e o Quadro Demonstrativo dos Cargos em Comissão e das Funçôes de Confiança do Ministério da Educação, remaneja cargos em comissão e funçóes de confiança e transforma cargos em comissão do Grupo-Direção e Assessoramento Superiores - DAS e Funçóes Comissionadas do Poder Executivo - FCPE. http:// www.planalto.gov.br/ccivil_03/_ato2019-2022/2019/Decreto/D9665.htm

Domingos Sobrinho, M. (2013). Universidade Tecnológica ou Instituto Federal de Educação, Ciência e Tecnologia? Ministério da Educação. http://portal.mec.gov.br/setec/arquivos/pdf1/artigo_moises.pdf

França, M. G., \& Teixeira, R. I. de O. (2016). Políticas de Educação Especial no Ensino Médio e Educação Profissional: Um olhar para o contexto do Instituto Federal do Espírito Santo. In S. L. Victor, \& I. M. de Oliveira (Org.), Educação Especial: política e formação de professores. (pp. 61-78). ABPEE.

Lei no 9.394, de 20 de dezembro de 1996. Estabelece as diretrizes e bases da educação nacional. http:// www.planalto.gov.br/ccivil_03/LEIS/L9394.htm

Lei 11.892, de 29 de dezembro de 2008. Institui a Rede Federal de Educação Profissional, Científica e Tecnológica, cria os Institutos Federais de Educação, Ciência e Tecnologia, e dá outras providências. http://www.planalto.gov.br/ccivil_03/_ato2007-2010/2008/lei/111892.htm

Lei no 12.711, de 29 de agosto de 2012. Dispóe sobre o ingresso nas universidades federais e nas instituiçôes federais de ensino técnico de nível médio e dá outras providências. http://www.planalto. gov.br/ccivil_03/_ato2011-2014/2012/lei/112711.htm

Lei no 13.409, de 28 de dezembro de 2016. Altera a Lei no 12.711, de 29 de agosto de 2012, para dispor sobre a reserva de vagas para pessoas com deficiência nos cursos técnico de nível médio e superior das instituiçôes federais de ensino. http://www.planalto.gov.br/ccivil_03/_ato2015-2018/2016/lei/ 113409.htm

Lei $n^{\circ}$ 13.146, de 6 de julho de 2015. Institui a Lei Brasileira de Inclusão da Pessoa com Deficiência (Estatuto da Pessoa com Deficiência). http://www.planalto.gov.br/ccivil_03/_ato2015-2018/2015/ lei/l13146.htm

Lei $n^{\circ} 13.530$, de 7 de dezembro de 2017. Altera a Lei no 10.260, de 12 de julho de 2001, a Lei ${ }^{\circ}$ 9.394, de 20 de dezembro de 1996 (Lei de Diretrizes e Bases da Educaçáo Nacional), a Lei no 8.958, de 20 de dezembro de 1994, a Lei no 9.766, de 18 de dezembro de 1998, a Lei no 8.745, de 9 de dezembro de 1993, a Lei no 12.101, de 27 de novembro de 2009, a Lei no 12.688, de 18 de julho de 2012, e a Lei no 12.871 , de 22 de outubro de 2013; e dá outras providências. http://www. planalto.gov.br/ccivil_03/_ato2015-2018/2017/lei/l13530.htm

Marques, C. L. (2014). Educação Profissional: o ingresso, as tecnologias e a permanência dos alunos com deficiência no Instituto Federal de Brasilia [Dissertação de Mestrado, Universidade de Brasília]. RepositóriodaUniversidadedeBrasília.https://repositorio.unb.br/bitstream/10482/15892/1/2014_ ClaudiaLuizaMarques.pdf

Mendes, E. G., Vilaronga, C. A. R., \& Zerbato, A. P. (2014). Ensino colaborativo como apoio à inclusão escolar: unindo esforços entre educação comum e especial. UFSCar.

Mendes, K. A. M. O. (2017). Educação Especial inclusiva nos institutos federais de educação, ciência e tecnologia brasileiros [Tese de Doutorado, Universidade Federal de Goiás, Faculdade de Educação]. Repositório da Universidade Federal de Goiás. https://repositorio.bc.ufg.br/tede/handle/tede/8139 
Nota Técnica - SEESP/GAB/No 9, 2010. Orientaçôes para a Organização de Centros de Atendimento Educacional Especializado. http://portal.mec.gov.br/index.php?option=com_ docman\&view=download\&alias=4683-nota-tecnica-n9-centro-aee \&Itemid=30192

Política Nacional de Educação Especial na perspectiva da educação Inclusiva (2008). http://portal. mec.gov.br/index.php?option=com_docman\&view=download $\&$ alias=16690-politica-nacionalde-educacao-especial-na-perspectiva-da-educacao-inclusiva-05122014\&Itemid=30192

Portaria Normativa $n^{\circ}$ 4, de 29 de janeiro de 2018. Ministério da Educação Secretaria de Educação Profissional e Tecnológica Instituto Federal Catarinense. http://ifc.edu.br/wp-content/ uploads/2018/02/Portaria-Normativa-004-2018-Regulamento-de-Atendimento-EducacionalEspecializado-do-IFC.pdf

Resolução CNE/CEB no 2, de 11 de setembro de 2001. Diretrizes nacionais para a educação especial na educação básica. http://portal.mec.gov.br/cne/arquivos/pdf/CEB0201.pdf

Resolução CNE/CEB no 4, de 2 de outubro de 2009. Institui Diretrizes Operacionais para o Atendimento Educacional Especializado na Educação Básica, modalidade Educação Especial. http://portal.mec. gov.br/dmdocuments/rceb004_09.pdf

Resolução no 19, de 18 de março de 2019. Aprova o Regulamento do Atendimento Educacional Especializado (AEE) no âmbito do Instituto Federal de Educação, Ciência e Tecnologia Baiano. https://www.ifbaiano.edu.br/unidades/lapa/files/2019/12/Resolucao-19-2019.pdf

Santos, J. R., \& Vilaronga, C. A. R. (2019). O Planejamento Educacional Individualizado e a ação dos Napnes: o que apontam as diretrizes [Apresentação de artigo]. Colóquio Internacional de Educação Especial e Inclusão Escolar, Florianópolis, Brasil. https://proceedings.science/cintedes-2019/ papers/o-planejamento-educacional-individualizado-e-a-acao-dos-napnes--o-que-apontam-asdiretrizes

Schmidt, M. de A. (2010). Os institutos de educaçâo, ciência e tecnologia: um estudo da expansão da rede federal de educação profissional e tecnológica [Dissertação de Mestrado, Faculdade de Educação da Universidade de Passo Fundo]. Biblioteca Digital da UPF. http://tede.upf.br:8080/jspui/handle/tede/686

Severino, A. J. (2017). Metodologia do trabalho cientifico. Cortez.

Waldemar, T. M. N. (2012). Inclusão educacional de pessoas com deficiência no Instituto Federal de Minas Gerais [Dissertação de Mestrado, Centro Universitário UNA]. Belo Horizonte, Minas Gerais, Brasil.

Zerbato, A. P., \& Oliveira, S. P. S. (2018). O Atendimento Educacional Especial no Instituto Federal Baiano: concepçóes iniciais da experiência no Campus Uruçuca [Apresentação de artigo]. 80 Congresso Brasileiro de Educação Especial, Universidade Federal de São Carlos, São Carlos. https://proceedings.science/cbee/cbee-2018/papers/o-atendimento-educacional-especializado-noinstituto-federal-baiano--concepcoes-iniciais-da-experiencia-no-campus-urucuc-

Recebido em: 19/12/2019

Reformulado em: 24/04/2020

Aprovado em: 06/07/2020 
ZERBATO, A.P.; VILARONGA, C.A.R.; SANTOS, J.R. 